\title{
Genç Kadın Kros ve Alp Kayakçılarında İzokapnik Tamponlama Fazının Karşılaştırılması
}

\section{Selcen KORKMAZ ERYILMAZ ${ }^{* 1}$, Metin POLAT ${ }^{2}$}

${ }^{1}$ Çukurova Üniversitesi Beden Eğitimi ve Spor Yüksekokulu, Adana, ORCID iD:0000-0002-3680-3580

${ }^{2}$ Erciyes Üniversitesi Beden Ĕgitimi ve Spor Yüksekokulu, Kayseri, ORCID iD:0000-0001-7299-0531

$\ddot{\mathbf{O z}}$ Orijinal Makale

Bu çalışma, genç kadın kros ve alp kayakçılarının izokapnik tamponlama faz değerlerini birbirleriyle karşılaştırmak amacıyla çalışılmıştır. Araştırmaya, uluslararası düzeyde yarışmalara katılan 10 genç kadın kros kayakçısı ve 8 genç kadın alp kayakçısı katılmıştır. Maksimal oksijen alımı $\left(\mathrm{VO}_{2 \max }\right)$, solunumsal eşik (SE) ve solunumsal kompenzasyon noktası (SKN) değerleri †'koşu bandında şiddeti giderek artan egzersiz test protokolü uygulanarak tespit edilmiștir.SE ve SKN değerleri V-Slope yöntemi ile belirlenmiştir. İzokapnik tamponlama (IKT) fazı, SKN ile SE arasındaki fark olarak hesaplandı ve hem mutlak hem de göreceli $\mathrm{VO}_{2}$ (İKTVO2) ve koşu hızı (IKKTHIz) değerleri ile ifade edildi. SE ve SKN karşılık gelen $\mathrm{VO}_{2}$, kalp atımı hızı ve koşu hızı tespit edilerek, $\mathrm{VO}_{2 \max }$ 'nin ve maksimal koşu hızının yüzdesi cinsinden görece değerleri hesaplandı. Tükenme zamanı testin toplam süresi olarak belirlendi.Kros kayakçıları $\mathrm{VO}_{2 \max }$, maksimal koşu hızı, tükenme zamanı, hem mutlak hem de göreceli SE değerleri ve mutlak SKN değerleri alp kayakçılarına kıyasla anlamlı olarak yüksek bulunurken $(\mathrm{P}<0.05)$, görece SKN değerleri arasında istatistiksel olarak anlamlı fark görülmedi ( $>0.05$ ). Hem mutlak hem de görece İKTvo2 değerleri alp kayakçılarında kros kayakçılarına kıyasla istatistiksel olarak daha yüksek bulundu $(\mathrm{p}<0.05)$. Görece İKT $T_{\text {Hz }}$ değerleri alp kayakçılarında kros kayakçılarına kıyasla anlamlı olarak yüksek bulunurken $(\mathrm{p}<0.05)$, mutlak İKT $\mathrm{HIZ}_{\mathrm{H}}$ değerleri iki grupta istatistiksel olarak benzerlik gösterdi ( $>00.05)$. Araştırma bulgularımız, alp kayakçıların kros kayakçılarına kıyasla aerobik kapasitelerinin daha düşük ve solunumsal eşiğe daha erken girdiklerini, öte yandan izokapnik tamponlama fazlarının daha geniş ve eşik sonrası egzersize toleranslarının daha yüksek olduğunu göstermiştir.

Anahtar kelimeler: Antrenman, maksimal oksijen alımi, solunumsal eşik, solunumsal kompenzasyon noktasi, tampon kapasitesi 


\section{A Comparison of Isocapnic Buffering Phase of Young Female Cross-Country and Alpine Skiers}

\begin{abstract}
The purpose of this study was to compare the isocapnic buffering phase in young female cross-country skiers and alpine skiers. International level young female skiers including ten cross-country skiers and eight alpine skiers took part in the study. Maximal oxygen uptake $\left(\mathrm{VO}_{2 \max }\right)$, ventilatory threshold $(\mathrm{VT})$ and respiratory compensation point $(\mathrm{RCP})$ were determined using an incremental treadmill exercise test. VT and RCP were determined using the $\mathrm{V}$-slope method. The isocapnic buffering (ICB) phase was calculated as the difference in $\mathrm{VO}_{2}\left(\mathrm{ICB}_{\mathrm{VO}}\right.$ ) and running speed (ICBSPEED) between RCP and VT and expressed in either absolute or relative values. The values of $\mathrm{VO}_{2}$, heart rate, and running speed corresponding to the VT and RCP were identified. Relative VT and RCP values were recorded as a percentage of $\mathrm{VO}_{2 \max }$ and maximal running speed. Time to exhaustion was determined as the total duration of the test. $\mathrm{VO}_{2 \max }$, maximal running speed, time to exhaustion, both absolute and relative VT values and absolute RCP values were higher in the cross-country skiers than in the alpine skiers $(\mathrm{P}<0.05)$, whereas relative RCP showed similar values in both group $(\mathrm{p}>0.05)$. Absolute ICB SPEED showed similar values in both group ( $p>0.05$ ), whereas absolute and relative ICBvo2 and relative ICBSPEED were found to be significantly higher in alpine skiers than in cross-country skiers $(\mathrm{P}<0.05)$. The results of this study indicated that the aerobic capacity and ventilatory threshold lower in alpine skiers than in cross-country skiers, while the isocapnic buffering phase and the highintensity exercise tolerance were higher in alpine skiers.
\end{abstract}

Original Article

Article Info

Received: 22.04.2018

Accepted: 11.06.2018

Online Published: 30.06.2018

\author{
Keywords: \\ Buffering capacity, maximal \\ oxygen uptake, respiratory \\ compensation point, training, \\ ventilatory threshold
}




\section{GíRiş}

Kardiyo pulmoner egzersiz testleriyle belirlenen solunumsal eşik ve solunum kompenzasyon noktası, özellikledayanıklılık sporcularında antrenmanların takibinde ve antrenman programı hazırlanmasında kullanılmaktadır (Seiler ve Kjerland, 2006). Anaerobik eşik (AE), şiddeti kademeli olarak artan egzersiz testi sırasındakan laktat (laktat eşiği) ölçümlerinin yanı sıra, solunumsal eşik (SE) olarak adlandırılannon-invaziv gaz değişim metotları ile de tahmin edilebilir (Beaver, Wasserman ve Whipp, 1986; Wasserman, 1984). Egzersizin belirli bir seviyesinden sonra aerobik metabolizma tarafindan üretilen karbondioksite ilave olarak, biriken laktik asitten ayrışan hidrojen iyonlarının $\left(\mathrm{H}^{+}\right)$bikarbonat ile tamponlanması sonucu karbondioksit üretiminde artış görülür. $\mathrm{H}^{+}$nin tamponlanmasıyla açığa çıkan nonmetabolik karbondioksite cevap olarak ventilasyon hızlanmaya başlar (Wasserman, 1984). SE, dakika ventilasyonu (VE) ve karbondioksit üretimi $\left(\mathrm{VCO}_{2}\right)$ ile oksijen alımı $\left(\mathrm{VO}_{2}\right)$ arasındaki doğrusallığın bozulduğu noktaya karşılık gelir. $\mathrm{H}^{+}$dolaşımdaki bikarbonatın tamponlama kapasitesini aşarsa, kan pH'sının asit tarafa kaymasına neden olur ve oluşan asidoz karotid cisimciklerini uyararak hiperventilasyona neden olur (Wasserman, 1984). VE ile $\mathrm{VCO}_{2}$ arasındaki ilişkiyi gösteren eğrinin eğimi hiperventilasyonla dikleşir. Bu ilave ventilasyon yanıtı solunumsal kompenzasyon noktası (SKN) olarak adlandırılır (Meyer, Faude, Scharhag, Urhausen ve Kindermann, 2004). Şiddeti kademeli olarak artan egzersiz sirasında tespit edilen SE ile SKN arasındaki bölge, izokapnik tamponlama (IKT) fazı olarak adlandırılır. İzokapnik tamponlama (İKT) fazı egzersize bağlı metabolik asidozun kompenzasyonunu yansitır (Whipp, Davis ve Wasserman, 1989). SKN ile egzersiz bitimi arasındaki bölge ise, hipokapnik hiperventilasyon (HHV) fazı olarak adlandırılır (Chicharrro, Hoyos ve Lucia, 2000; Oshima, Miyamoto, Tanaka, Wadazumi, Kurihara ve diğerleri, 1997).

İzokapnik tamponlama (İKT) fazının uzunluğu, tamponlama kapasitesi, laktat kinetiği yanında karotis cisimlerinin egzersize bağlı metabolik asidoza duyarlılığı ile ilişkili olabilir (Aveseh ve Mohammad, 2015; Hasanli, Nikooie, Aveseh ve Mohammad, 2015; Rausch, Whipp, Wasserman ve Huszczuk, 1991; Whipp Davis ve Wasserman, 1989). Baz1 araştırmacılar, İKT fazının yüksek olmasının sporcuların aerobik kapasitesine katkıda bulunduğunu belirtmişlerdir (Oshima, Miyamoto, Tanaka, Wadazumi, Kurihara ve diğerleri, 1997; Hirakoba ve Yunoki, 2002). Öte yandan bazı araştırmacılar, İKT fazının dayanıklılık performansıyla ilişkili olmadığını ileri sürmüşlerdir (Bentley, Vleck ve Millet, 2005). Yakın zamanda görece IKKT fazının, sporcuların hem aerobik hem de anaerobik kapasitelerinin tahmininde kullanılabileceği gösterilmiştir (Hasanli Nikooie, Aveseh ve Mohammad, 2015).

Şiddeti kademeli olarak artan egzersiz testi sırasında İKT fazının değerlendirilmesi, sporcuların tampon kapasitesi hakkında non-invaziv olarak tahmini bilgi vermesi nedeniyle önemli olabilir. İKT fazının uzunluğu, farklı spor dallarındaki sporcularda yapılan antrenmanların şiddetine ve kapsamına bağlı olarak değişkenlik gösterebilir (Hasanli Nikooie, Aveseh ve Mohammad, 2015; Hirakoba ve Yunoki, 2002; Röcker, Striegel, Freund ve Dickhuth, 1994). Literatürde aerobik ve anaerobik antrenman yapan sporcularda İKT fazını birbirleriyle karşılaştıran çok az çalışmaya rastlanmaktadır. Bu çalışmalarda, İKT fazı esnasına kan laktat değerlerindeki artışın, anaerobik antrenman yapan sporcularda, aerobik dayanıklılık antrenmanları yapan sporculara göre daha fazla olduğu gösterilmiştir (Hasanli 
Nikooie, Aveseh ve Mohammad, 2015; Hirakoba ve Yunoki, 2002; Röcker, Striegel, Freund ve Dickhuth, 1994). Literatürde anaerobik antrenmanlı kadın sporcular ile dayanıklılık antrenmanlı kadın sporcular arasında İKT fazı esnasına $\mathrm{VO}_{2}$ değerlerini karşılaştıran araştırmaya rastlanmamıştır.

Kros kayağı (kayaklı koşu) yarışmalarının 10 ila 120 dakika arasında değişen sürelerde gerçekleştirildiği göz önünde bulundurulduğunda, kros kayakçılarının aerobik kapasitelerinin düzeyinin yüksek olması beklenir (Staib, Im, Caldwell ve Rundell, 2000). Bu nedenle kros kayakçılarıantrenman programlarında, ağırlıklı olarak aerobik kapasitelerini geliştirmeye yönelik dayanıklılık antrenmanlarına yer verirler (Holmberg, 2015; Sandbakk ve Holmberg, 2014; Seiler ve Kjerland, 2006). Öte yandan yarışmaların süresi 45 saniye ile 3 dakika arasında değişen alp kayağında, sportif performans beklentisi göz önünde bulundurulduğunda, alp kayakçılarının anaerobik güç değerlerinin yüksek olması gerekir (White ve Johnson, 1991). Bu nedenle alp kayakçıları sürat çalışmaları, direnç egzersizleri, yön değiştirme dirilleri ve pliyometrik egzersizler gibi ağırlıklı olarak anaerobik egzersizleri içeren antrenman programları uygularlar (Bosco, Cotelli, Bonomi, Mognoni ve Roi, 1994; Hydren, Volek, Maresh, Comstock ve Kraemer, 2013).

Sporcuların İKT faz değerlerinin ölçülmesi, farklı antrenman uyaranlarına cevap olarak gelişen fizyolojik adaptasyonların anlaşılmasına yardımcı olabilir. Bildiğimiz kadarıyla literatürde, kadın kayaklı koşucu ve alp kayakçılarında İKT fazını inceleyen bir çalışma bulunmamaktadır. $\mathrm{Bu}$ çalışma, kadın kros ve alp kayakçılarının İKT faz değerlerini birbirleriyle karşılaştırmak amacıyla çalışılmıştır.

\section{YÖNTEM}

\section{Çalışma Grubu}

Araştırmaya, 10 genç kadın kros kayakçısı (16.1 \pm 1.1 yaş, $163.6 \pm 5.7 \mathrm{~cm}$ boy, $53.4 \pm 8.9 \mathrm{~kg}$ vücut ağırlı̆̆ı) ve 8 genç kadın alp kayakçısı $(16.9 \pm 1.8$ yaş, $159.8 \pm 4.5 \mathrm{~cm}$ boy, $52.6 \pm 6.5$ kg vücut ağırlığı) olmak üzere toplam 18 Türk Milli Takım sporcusu katılmıştır. Araştırma için Erciyes Üniversitesi Tıp Fakültesi Etik Kurulundan onay alınmıştır (No 2017/554).Tüm ölçümler Erciyes Üniversitesi Yüksek İrtifa ve Spor Bilimleri Araştırma ve Uygulama Merkezi Laboratuarında gerçekleştirilmiştir.

\section{Kardiyopulmoner Egzersiz Testi}

Sporcuların $\mathrm{VO}_{2 \max }$, SE ve SKN değerleri koşu bandında (h/p/Cosmos Quasar med, Nussdorf-Traunstein, Germany) kardiopulmoner egzersiz test bataryası kullanılarak tespit edilmiştir. Test sırasında solunum havasında meydana gelen değişimler, Cosmed Quark PFTErgo gaz analiz sistemi (Cosmed Srl, Rome, Italy) ile her bir soluk için (breath-by-breath) ayrı ayrı ölçülerek kayıt edildi. $\mathrm{VO}_{2 \max }$ belirlenmesinde verilerin analizi 15 saniyelik zaman aralıkları ile ortalama değerleri alınarak gerçekleştirilmiştir. Buna karşın eşik hesaplamalarında verilerinin 5 saniyelik ortalama değerleri alınarak oluşturulan yeni veri gurubu kullanılmıştır. Her testten önce akış sensörü ve gaz analizör bileşenleri üretici 
firmanın önerdiği şekilde kalibre edilmiştir. Test süresince kalp atım hızları telemetrik kalp hızı monitörü (Polar RS800 SD, Finland) aracılığı ile kaydedilmiştir.

Egzersiz testine başlamadan önce her bir sporcu koşu bandında 6 dakika süre ile kendi temposunda 1sındırıldı, ardından yaklaşık 3 dakika esnetme egzersizleri yaptırıldı. Sporculardan \% 5 eğimde $7 \mathrm{~km} /$ saat'lik koşu hızı ile egzersize başlamaları istendi ve izleyen düre zarfında koşu hızı dakikada $1 \mathrm{~km} / \mathrm{saat}$ arttırılarak, sporcuların tükeninceye kadar koşturulması sağlandı.Sporcuların test sırasında maksimal kalp atım hızına ulaşmaları (220yaş), ekspire edilen karbondioksit $\left(\mathrm{VCO}_{2}\right)$ ile alınan oksijenin $\left(\mathrm{VO}_{2}\right)$ anlık oranı olarak ifade edilen solunum değişim oranının (RER) 1.10'dan daha yüksek değerlere çıkması ve egzersiz yoğunluğu artmasına karşın oksijen alımının platoda kalması, $\mathrm{VO}_{2 \max }$ 'a ulaşma kriterleri olarak kabul edildi. Bu kriterlerden en az iki tanesinin aynı anda gerçekleştiği en yüksek 15 saniyelik ortalama oksijen alım değeri, $\mathrm{VO}_{2 \max }(\mathrm{ml} / \mathrm{kg} / \mathrm{dak})$ olarak kabul edildi. Tükenme zamanı testin toplam süresi olarak belirlendi. Maksimal solunum değişimi oranı $\left(\mathrm{CO}_{2} / \mathrm{O}_{2}\right)$, egzersiz testinin son aşamasında elde edilen en yüksek 15 saniyelik ortalama değer olarak kabul edildi.

\section{Solunumsal eşik ve solunum kompanzasyon noktasının belirlenmesi}

Sporcuların SE ve SKN değerleri V-Slope yöntemi ile belirlendi (Beaver, Wasserman ve Whipp, 1986). SE belirlenmesi için $\mathrm{VCO}_{2}$ 'ye karşıl1k gelen $\mathrm{VO}_{2}$ eğrisinin, SKN belirlenmesi için ise $\mathrm{VE}$ karşılık gelen $\mathrm{VCO}_{2}$ eğrisinin grafiği çizildikten sonra, lineer regresyon analizi yapılarak iki regresyon çizgisinin kesişme noktası tespit edildi (şekil 1). SE ve SKN noktasına karşılık gelen $\mathrm{VO}_{2}(\mathrm{ml} / \mathrm{kg} /$ dak$)$ değeri, koşu hızı $(\mathrm{km} / \mathrm{saat})$, kalp atım hızı tespit edildi. Ayrıca görece SE ve SKN değerleri, $\mathrm{VO}_{2 \max }$ ve maksimal koşu hızının yüzdesi olarak hesapland1.
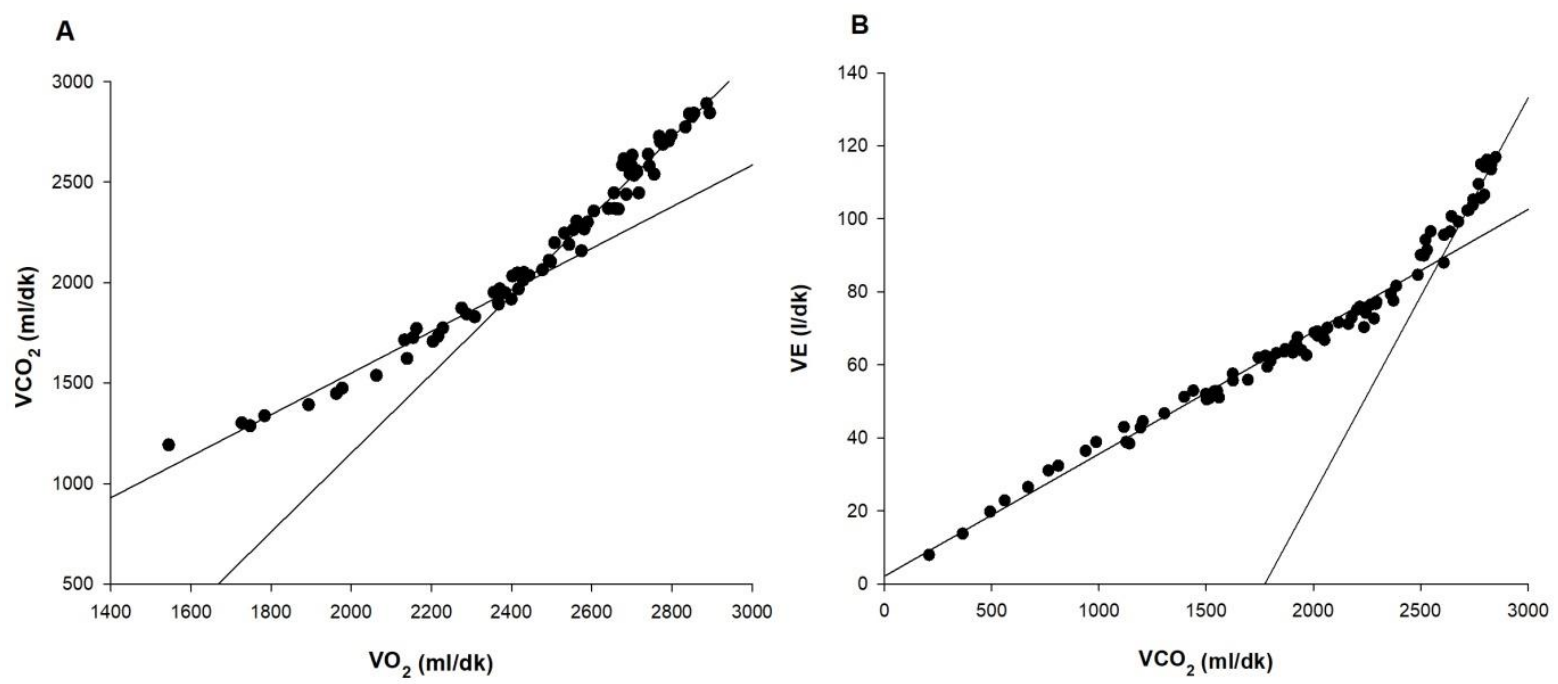

Şekil 1. Bir sporcunun solunumsal eşiğini (A) ve solunum kompenzasyon noktasını (B) gösteren örnekler. 


\section{İzokapnik tamponlama ve hipokapnik hiperventilasyon fazlarının belirlenmesi}

IKT fazı, SKN ile SE arasındaki fark olarak hesaplandı ve hem mutlak hem de göreceli $\mathrm{VO}_{2}$

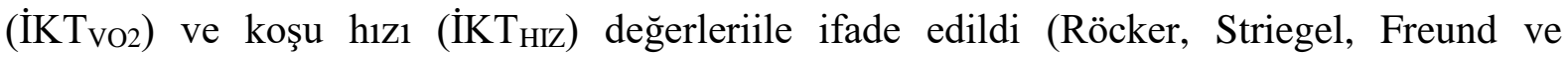
Dickhuth, 1994; Oshima, Tanaka ve Miyamoto, 1998). İKT fazıngöreceli değerleri Röcker ve arkadaşları tarafından tanımlanan RCP yüzdesi olarak hesaplandı (eşitlik 1) (Röcker Striegel, Freund ve Dickhuth, 1994). HHV fazı, egzersiz bitimi ile SKN arasındaki $\mathrm{VO}_{2}\left(\mathrm{HHV}_{\mathrm{VO}}\right)$ ve koşu hızı farkı (HHV ifade edildi. HHV fazın göreceli değerleri $\mathrm{VO}_{2 \max }$ 'n ve maksimal koşu hızının yüzdesi olarak hesaplandı (Oshima, Tanaka ve Miyamoto, 1998).

Görece İKT= $(\mathrm{SKN}-\mathrm{SE}) \div \mathrm{SKN} \times 100$

\section{Verilerin Analizi}

Çalışmada sunulan verilerin tümü ortalama \pm standart sapma olarak verilmiş, $\mathrm{p}<0.05$ ile altındaki değerler istatistiksel olarak anlamlı kabul edilmiştir. Verilerin normal dağılıma uygunluğu Shapiro Wilk testi ile incelenmiştir. Normal dağılım gösteren veriler bağımsız gruplarda student $t$ testi, normal dağılım göstermeyen veriler ise parametrik olmayan Mann Whittney-U testi kullanılarak analiz edilmiştir. Ayrıca sonuçların daha iyi yorumlanabilmesi için etki büyüklügüü, Cohen's d formülü kullanılarak hesaplanmıştır. Etki büyüklügü (EB) aldığ 1 değere göre $\mathrm{d} \geq 0.2$ "önemsiz", $0.2 \leq \mathrm{d} \leq 0.5$ "küçük", $0.5 \leq \mathrm{d} \leq 0.8$ "orta" ve $0.8 \geq$ d"büyük" olarak yorumlanmaktadır (Thalheimer ve Cook, 2016). İstatistik hesaplamalarının tümü Windows için yazılmış olan SPSS 21 (IBM SPSS Statistics 21 Inc. Chicago, IL) paket programı kullanılarak yapılmıştır. Lineer regresyon analizleri, Sigma Plot programı (Sigma Plot 12.0, Systat Software Inc., Chicago, ABD) kullanılarak gerçekleştirilmiştir.

\section{BULGULAR}

Yapılan istatistiksel değerlendirmede kros kayakçıların $\mathrm{VO}_{2 \max }$, SE ve SKN'a karşılık gelen $\mathrm{VO}_{2}$ ve koşu hızı, maksimal koşu hızı, tükenme zamanı ve SE karşılık gelen kalp atım hızıdeğerleri alp kayakçılarına göre anlamlı olarak yüksek bulunmuştur $(\mathrm{p}<0.05)$. İki grubun maksimal kalp atım hızı ve SKN'a karşılık gelen kalp atım hızı arasında anlamlı farklılık görülmedi ( $\mathrm{p}>0.05$ ). Alp kayakçılarının solunum değişim oranlarının kros kayakçılarına kıyasla anlamlı olarak daha yüksek olduğu tespit edilmiştir $(\mathrm{p}<0.05)$. SE'in $\mathrm{VO}_{2 \max }$ ve maksimal koşu hızının yüzdesi olarak ifade edilen görece değerleri kros kayakçılarında alp kayakçılarına oranla anlamlı olarak daha yüksek bulundu $(\mathrm{p}<0.05)$. Öte yandan iki grubun SKN'nın $\mathrm{VO}_{2 \max }$ ve maksimal koşu hızının yüzdesi olarak ifade edilen görece değerleri arasında istatistiksel olarak anlamlı fark görülmedi $(\mathrm{p}>0.05)$. Hem mutlak hem de görece İKTVO2 değerleri alp kayakçılarında kros kayakçılarına kıyasla istatistiksel olarak daha

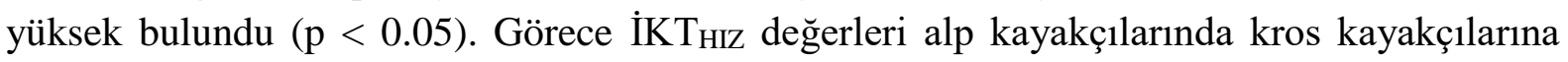

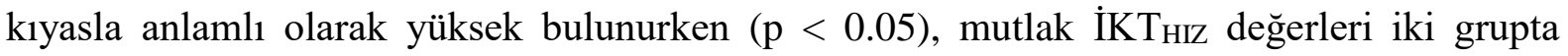
istatistiksel olarak benzerlik gösterdi ( $p>0.05$ ). Hem mutlak hem de görece $\mathrm{HHV}_{\mathrm{VO} 2}$ ve $\mathrm{HHV}_{\mathrm{HIZ}}$ değerlerinde iki grup arasında istatistiksel olarak anlamlı farklılık olmadığ edilmiştir $(\mathrm{p}>0.05)$. 
Tablo 1. Alp ve kros kayakçılarının solunumsal eşik, solunum kompenzasyon noktası, maksimal oksijen alımı, izokapnik tamponlama ve hipokapnik hiperventilasyon değerleri.

\begin{tabular}{|c|c|c|c|c|}
\hline Değişkenler & Alp kayakçıları & Kros kayakçıları & $\mathrm{p}$ & EB \\
\hline $\mathrm{SE}_{\mathrm{VO} 2}\left(\mathrm{ml} \mathrm{kg} \mathrm{\textrm {min } ^ { - 1 } )}\right.$ & $35.4 \pm 3.1$ & $46.6 \pm 1.2^{*}$ & 0.001 & 5.15 \\
\hline $\mathrm{SE} \% \mathrm{VO}_{2 \max }$ & $83.3 \pm 4.9$ & $90.2 \pm 3.6^{*}$ & 0.004 & 1.71 \\
\hline $\mathrm{SE}_{\mathrm{HIz}}\left(\mathrm{km} \mathrm{h}^{-1}\right)$ & $8.1 \pm 0.3$ & $10.2 \pm 0.6^{*}$ & 0.001 & 4.6 \\
\hline $\mathrm{SE} \% \mathrm{H}_{1} \mathrm{Z}_{\max }$ & $70.8 \pm 5$ & $77.3 \pm 4.5^{*}$ & 0.01 & 1.45 \\
\hline $\mathrm{SE}_{\mathrm{KAH}}(\mathrm{atım} / \mathrm{dk})$ & $174.8 \pm 9.3$ & $184.5 \pm 6^{*}$ & 0.03 & 1.35 \\
\hline $\left.\mathrm{VO}_{2}(\mathrm{ml} \mathrm{kg} \mathrm{min})^{-1}\right)$ & $41.2 \pm 3.1$ & $50.1 \pm 1.9^{*}$ & 0.001 & 3.71 \\
\hline$\% \mathrm{VO}_{2 \max }$ & $96.9 \pm 1.35$ & $96.8 \pm 1.32$ & 0.83 & 0.08 \\
\hline $\mathrm{H} 1 \mathrm{z}\left(\mathrm{km} \mathrm{h}^{-1}\right)$ & $10.2 \pm 0.7$ & $11.9 \pm 0.3 *$ & 0.001 & 3.41 \\
\hline$\% \mathrm{H}_{1} \mathrm{Z}_{\max }$ & $89.1 \pm 3.6$ & $90.2 \pm 3.1$ & 0.51 & 0.35 \\
\hline $\mathrm{SKN}_{\mathrm{KAH}}(\mathrm{at} 1 \mathrm{~m} / \mathrm{dk})$ & $188.1 \pm 11$ & $196.7 \pm 10.3$ & 0.13 & 0.86 \\
\hline $\mathrm{VO}_{2 \max }\left(\mathrm{ml} \mathrm{kg} \mathrm{min}^{-1}\right)$ & $42.5 \pm 3.3$ & $51.7 \pm 2.2 *$ & 0.001 & 3.51 \\
\hline $\mathrm{H}_{1 Z_{\max }}\left(\mathrm{km} \mathrm{h}^{-1}\right)$ & $11.5 \pm 0.7$ & $13.2 \pm 0.6^{*}$ & 0.001 & 2.77 \\
\hline Tükenme zamanı (dk) & $4.8 \pm 0.6$ & $6.6 \pm 0.6^{*}$ & 0.001 & 3.17 \\
\hline $\mathrm{SDO}_{\max }$ & $1.17 \pm 0.04$ & $1.13 \pm 0.02 *$ & 0.04 & 1.36 \\
\hline $\mathrm{KAH}_{\max }(\mathrm{atım} / \mathrm{dk})$ & $197.5 \pm 9.5$ & $206.5 \pm 10.9$ & 0.1 & 0.93 \\
\hline Mutlak İKT $_{\mathrm{VO} 2}\left(\mathrm{ml} \mathrm{kg} \mathrm{min}^{-1}\right)$ & $5.8 \pm 1.8$ & $3.4 \pm 1.7 *$ & 0.01 & 1.45 \\
\hline Görece İKT $\mathrm{IO}_{2}$ & $14 \pm 4.2$ & $6.8 \pm 3.1^{*}$ & 0.001 & 2.08 \\
\hline Mutlak İKT ${ }_{\mathrm{HIZ}}\left(\mathrm{km} \mathrm{h}^{-1}\right)$ & $2.1 \pm 0.8$ & $1.7 \pm 0.4$ & 0.19 & 0.68 \\
\hline Görece İKT & $20.3 \pm 6.9$ & $14.3 \pm 4.1^{*}$ & 0.03 & 1.13 \\
\hline 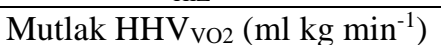 & $1.2 \pm 0.6$ & $1.6 \pm 0.7$ & 0.83 & 0.06 \\
\hline Görece $\mathrm{HHV}_{\mathrm{VO} 2}$ & $3.03 \pm 1.3$ & $3.1 \pm 1.3$ & 0.2 & 0.65 \\
\hline Mutlak HHV SPEED $\left(\mathrm{km} \mathrm{h}^{-1}\right)$ & $1.2 \pm 0.4$ & $1.3 \pm 0.4$ & 0.51 & 0.35 \\
\hline Görece $H_{H} V_{\text {SPEED }}$ & $10.8 \pm 3.6$ & $9.7 \pm 3.1$ & 0.82 & 0.26 \\
\hline
\end{tabular}

Ortalama \pm standart sapma, * Alp kayakçılarına göre istatistiksel anlamlı farklılığ ifade eder $(\mathrm{p}<0.05)$. EB = etki büyüklüğü (Cohen's d), $\mathrm{VO}_{2 \max }=$ maximal oxygen uptake, $\mathrm{SDO}_{\max }=$ Maksimal solunum değişimi oranı, $\mathrm{H}_{1 Z_{\max }}=$ maksimal koşu hızı, $\mathrm{SE}=$ Solunumsal eşik, $\mathrm{KAH}=$ Kalp atım hızı, $\mathrm{SKN}=$ Solunumun kompenzasyon noktası, karşılık gelen $\mathrm{VO}_{2}$, İKT = İzokapnik tamponlama fazı, $\mathrm{HHV}=$ Hipokapnik hiperventilasyon fazı.

\section{TARTIŞMA VE SONUÇ}

Kros kayakçılarında $\mathrm{VO}_{2 \max }$, maksimum hız, tükenme zamanı ve hem mutlak hem de görece SE değerlerinin alp kayakçılarına göre istatistiksel olarak daha yüksek bulunması, kros kayakçılarının aerobik kapasitelerinin beklenildiği gibi daha iyi olduğunu göstermektedir. Öte yandan, alp kayakçılarının hem mutlak hem de görece İKT faz değerlerinin kros kayakçılarına göre anlamlı olarak daha yüksek olduğu tespit edilmiştir. Alp kayakçılarında IKT faz değerlerinin yüksek bulunması, anaerobik antrenman uyaranlarının $\mathrm{H}^{+}$ni tamponlama kapasitesini geliştirdiğini ve bu gelişimin SE'in üzerinde görece daha uzun süre egzersize devam etmeye katkıda bulunabileceğini düşündürmektedir.

Bildiğimiz kadarıyla literatürde, sadece üç çalışma aerobik ve anaerobik antrenmanlı sporcular arasında İKT faz değerlerini karşılaştırmıştır. Bulgularımızla uyumlu olarak bu çalışmalarda, anaerobik antrenman yapan sporcularda IKT fazının aerobik dayanıklılık antrenmanları yapan sporculara kıyasla daha yüksek değerlerde olduğu gösterilmiştir (Hasanli, Nikooie, Aveseh ve Mohammad, 2015; Hirakoba ve Yunoki, 2002; Röcker, Striegel, Freund ve Dickhuth, 1994). Hirakoba ve arkadaşları, İKT fazında kan laktat düzeylerindeki artışın sprinterlerde uzun mesafe koşucularına kıyasla daha yüksek olduğunu bulmuşlardır (Hirakoba ve Yunoki, 2002). Röcker ve arkadaşları İKT fazını görece koşu hızı olarak hesapladıkları çalışmalarında, elit $400 \mathrm{~m}$ koşucularda İKT fazının aerobik dayanıklılık antrenmanları yapan sporculara kıyasla daha yüksek değerlerde olduğunu bildirmişlerdir 
(Röcker, Striegel, Freund ve Dickhuth, 1994). Ancak araştırmalarına katılan 400 m koşucular ile aerobik antrenman yapan sporcuların maksimal koşu hızı ve $\mathrm{VO}_{2 \max }$ değerleri arasında istatistiksel olarak anlamlı farklılık olmadığı görülmektedir. Benzer şekilde Hasanli ve arkadaşlarının yaptığı çalışmada, IKKT fazı sırasında görece laktat artışının sprint antrenmanları yapan bisikletçilerde aerobik dayanıklılık antrenmanları yapan bisikletçilere oranla anlamlı olarak daha yüksek düzeyde olduğu, öte yandan iki grubun $\mathrm{VO}_{2 m a x}$ değerleri arasında istatistiksel olarak anlamlı farklılık olmadığı görülmektedir (Hasanli, Nikooie, Aveseh ve Mohammad, 2015). Araştırmamıza katılan sporcuların yaptıkları spor branşları ve aerobik kapasitelerinin düzeyi göz önünde bulundurulduğunda, sunulan çalışmanın aerobik ve anaerobik antrenmanlı sporcularda İKT fazının araştırılması için uygun bir model olduğunu söyleyebiliriz.

Antrenmanlı bireylerde, antrenmansız bireylere kıyasla İKT fazının daha uzun olduğu, SKN'nın da egzersizin daha yüksek şiddetlerinde meydana geldiği gösterilmiştir (Lenti, De Vito, Scotto di Palumbo, Sbriccoli, Quattrini ve diğerleri, 2011). Bu nedenle SKN yüksek olan kişilerde İKT faz aralığının da daha uzun olabileceği ifade edilmektedir (Oshima, Miyamoto, Tanaka, Wadazumi, Kurihara ve diğerleri, 1997). Öte yandan sunulan çalışmada, alp kayakçıları ile kros kayakçılarının görece SKN değerleri arasında istatistiksel olarak anlamlı farklılık olmadığ 1 tespit edilmiştir. Bu bulgu araştırmamıza katılan her iki grubun da düzenli olarak antrenman yapan sporcular olmasından kaynaklanıyor olabilir. Bu nedenle, alp kayakçılarında kros kayakçılarına kıyasla daha uzun İKT fazının tespit edilmesi, görece SE değerlerinin daha düşük olmasından kaynaklandığını düşündürmektedir. Alp kayakçıları şiddeti kademeli olarak artan egzersiz testi sırasında, SE'in üzerinde görece daha uzun süre egzersize devam edebildiler. Anaerobik antrenmanlı sporcularda tampon kapasitesinin artırılması, anaerobik performans kapasitesinin geliştirilmesine katkıda bulunan bir faktör olabilir (Parkhouse, Mckenzie, Hochachka ve Ovalle, 1985).

$\mathrm{VO}_{2 \max }$ ve $\mathrm{SE}$, aerobik dayanıklılığın değerlendirilmesinde kullanılan en önemli fizyolojik değişkenlerdir (Helgerud, 1994). Bu nedenle, kros kayakçıların $\mathrm{VO}_{2 \max }$ yanı sıra $\mathrm{SE}$ değerlerinin de yüksek olması beklenir. Yapılan antrenmanların şiddetine ve kapsamına bağlı olarak vücutta farklı fizyolojik adaptasyonlar gelişir (Docherty ve Sporer, 2000). Geleneksel olarak kros kayakçıları, antrenmanlarının çoğunda SE'in altındaki şiddetlerde yapılan yüklenmelerle antrene edilirler (Seiler ve Kjerland, 2006). SE'in biraz altındaki şiddetlerde yapılan antrenmanların, pulmoner difüzyon kapasitesinde, hemoglobin bağlanma kapasitesinde ve kardiyak debide artış gibi başlıca santral adaptasyonları sağladığı ve bu adaptasyonların SE arttırdı ğ belirtilmektedir (Docherty ve Sporer, 2000). Kros kayakçıların alp kayakçılarına kıyasla yüksek SE değerlerine sahip olmalarının bir başka açıklaması, bu grubun genetik yapısıyla ilişkili olabilir. Görece SE değerlerinin belirlemede, yavaş kasılan kas liflerinin yüzdesi yanında kasın respiratuar kapasitesi önemli rol oynayabilir (Ivy, Withers, Van Handel, Elger and Costill, 1980).

Muhtemelen antrenmanlarda farklı metabolik yolakların kullanılmasına bağlı olarak, aerobik ve anaerobik antrenmanlı sporcularda SE, SKN ve dolayısıyla İKT faz değerleri farklılık gösterir. Bazı araştırmacılar, anaerobik metabolizmayı içeren yüksek şiddetli antrenmanların, tamponlama kapasitesini geliştirerek SKN'nı daha yüksek şiddetlere doğru kaydırdığı ve bu 
kaymanın İKT fazının uzamasına neden olduğunu düşünmektedirler (Chicharrro, Hoyos ve Lucia, 2000). Öte yandan aerobik metabolizmayı içeren antrenmanların, hem SE hem de SKN benzer oranda geliştirdiği gösterilmiştir (Chicharrro, Hoyos ve Lucia, 2000). Bu nedenle, yüksek şiddetli antrenmanların SKN üzerindeki etkisinin SE'den daha fazla olabileceğini söylemek mümkün olabilir. Alp kayağında yapılan antrenmanlar sırasında ağırlıklı olarak anaerobik enerji yollakları uyarılır (Hydren ve diğerleri, 2013). Yüksek şiddetli egzersizler sırasında büyük miktarda biriken laktat ve $\mathrm{H}^{+}$, kas $\mathrm{pH}$ 'sının düzenlenmesinden sorumlu sistemlerin adaptasyonları için önemli bir uyaran olabilir (Bishop, Girard ve Mendez-Villanueva, 2011). Nitekim yüksek şiddetli interval antrenmanların kasın tampon kapasitesini arttırdığı gösterilmiştir (Edge, Bishop ve Goodman, 2006). Ayrıca sprint antrenmanlarının kas tampon kapasitesini arttırdı̆̆ı, öte yandan aerobik dayanıklılık antrenmanlarıyla bu gelişimin sağlanamadığ 1 gösterilmiştir (Sharp, Costill, Fink ve King, 1986). Araştırma bulgularımız, alp kayakçılarında yapılan anaerobik antrenmanların, tamponlama kapasitesini geliştirerek SE'de herhangi birdeğişim olmadan SKN'da artışa yol açtığı ve sonuç olarak SKN fazını genişlettiğini düşündürmektedir.

Alp kayakçılarının SKN fazının daha uzun olmasının bir başka olası açıklaması, hızlı kasılan kas liflerinin yüzdesi olabilir. Hızlı kasılan kas lifleri yavaş kasılan kas liflerine kıyasla daha yüksek tamponlama kapasitesine sahip olabileceği belirtilmektedir (Nakagawa ve Hattori, 2002; Parkhouse ve Mckenzie, 1984). Anaerobik antrenmanlı sporcularda kas tamponlama kapasitesinin dayanıklılık sporcularından daha yüksek olduğu gösterilmiştir (Edge, Bishop, Hill-Haas, Dawson ve Goodman, 2006). İKT fazı sırasında, sprint antrenmanlı bisikletçilerde dayanıklılık bisikletçilerine kıyasla daha fazla $\mathrm{H}^{+}$'nin non-bikarbonat tampon sistemleri tarafından tamponlandığı bildirilmiştir (Hasanli Nikooie, Aveseh ve Mohammad, 2015).

Alp kayakçılarının egzersiz testi sırasında tükenme zamanı kros kayakçılarına kıyasla daha kısa olmasına rağmen solunum değişim oranı değerlerinin daha yüksek olduğu kaydedildi. Araştırmamızda kan laktat düzeylerini ölçemedik. Öte yandan alp kayakçılarında kros kayakçılarına kıyasla daha yüksek solunum değişim oranı değerlerinin tespit edilmiş olması, alp kayakçılarında egzersiz testi sırasında daha fazla laktikasitin biriktiğini dolaylı olarak göstermesi açısından önem taşımaktadır (Stringer, Wasserman ve Casaburi, 1995). İKT fazı esnasında laktat artışının, anaerobik antrenmanlı sporcularda aerobik antrenmanlı sporculardan daha yüksek düzeyde olduğu gösterilmiştir (Hasanli ve diğerleri, 2015; Hirakoba ve Yunoki, 2002; Bentley ve diğerleri, 2005). Bunun yanında, İKT fazı esnasındaki görece laktat artışı ile aerobik uygunluk $\left(\mathrm{VO}_{2 \max }\right.$ ve laktat eşiğine karşılık gelen $\left.\mathrm{VO}_{2}\right)$ arasında negatif ilişki olduğu bildirilmiştir (Hasanli, Nikooie, Aveseh ve Mohammad, 2015; Hirakoba ve Yunoki, 2002). Anaerobik antrenmanlardan sonra yüksek laktat konsantrasyonları, kas tampon kapasitesinin ve glikolitik enzimlerin artışı ile açıklanmaktadır (Sharp, Costill, Fink ve King, 1986; Mohr, Krustrup, Nielsen, Nybo, Rasmussen, Juel ve diğerleri, 2007). Alp kayakçıların kros kayakçılarına kıyasla SE değerlerinin düşük ve solunum değişim oranının yüksek bulunması antrenmanlarla gelişen anaerobik adaptasyonların bir sonucu olduğunu düşündürmektedir. 


\section{SONUÇ}

Araştırma bulgularımız, alp kayakçıların kros kayakçılarına kıyasla aerobik kapasitelerinin daha düşük ve solunumsal eşiğe daha erken girdiklerini, öte yandan izokapnik tamponlama fazlarının daha geniş ve eşik sonrası egzersize toleranslarının daha yüksek olduğunu göstermiştir. Anaerobik antrenmanlarla gelişen spesifik metabolik adaptasyonların bir sonucu olarak tampon kapasitesi gelişebilir ve bu gelişim sayesinde solunumsal eşik sonrası görece daha uzun süre egzersize devam edilebilir. Anaerobik antrenmanlı sporcularda daha uzun IKT fazının, yüksek şiddetli egzersize toleransın arttırılmasında rol oynayan önemli bir faktör olabilir.

\section{KAYNAKLAR}

Beaver, W. L., Wasserman, K., \& Whipp, B. J. (1986). A new method for detecting the anaerobic threshold by gas exchange. Journal of applied physiology, 60(6), 2020-2027.

Bentley, D. J., Vleck, V. E., \& Millet, G. P. (2005). The isocapnic buffering phase and mechanical efficiency: Relationship to cycle time trial performance of short and long duration. Canadian Society for Exercise Physiology, 30(1), 46-60.

Bishop, D., Girard, O., \& Mendez-Villanueva, A. (2011). Repeated-Sprint Ability - Part II Recommendations for Training. Sports medicine, 41(9), 741-756.

Bosco, C., Cotelli, F., Bonomi, R., Mognoni, P., \& Roi, G. S. (1994). Seasonal fluctuations of selected physiological characteristics of elite alpine skiers. European journal of applied physiology and occupational physiology, 69(1), 71-4.

Chicharrro, J., Hoyos, J., \& Lucia, A. (2000).Effects of endurance training on the isocapnic buffering and hypocapnic hyperventilation phases in Professional cyclists. British journal of sports medicine, 34, 450455.

Docherty, D. \& Sporer, B. (2000). A proposed model for examining the interference phenomenon between concurrent aerobic and strength training. Sports medicine, 30(6), 385-94.

Edge, J., Bishop, D., \& Goodman, C. (2006). The effects of training intensity on muscle buffer capacity in females. European journal of applied physiology, 96, 97-105.

Edge, E. J., Bishop, D., Hill-Haas, S., \& Dawson, B., Goodman, C. (2006). Comparison of muscle buffer capacity and repeated-sprint ability of untrained, endurance-trained and team-sport athletes. European journal of applied physiology, 96, 225-234.

Hasanli, M., Nikooie, R., Aveseh, M., \& Mohammad, F. (2015). Prediction of aerobic and anaerobic capacities of elite cyclists from changes in lactate during isocapnic buffering phase. Journal of strength and conditioning research, 29(2), 321-9.

Helgerud, J. (1994). Maximal oxygen uptake, anaerobic threshold and running economy in women and men with similar performance levels in marathons. European journal of applied physiology and occupational physiology, 68, 155-61.

Hirakoba, K., \& Yunoki, T. (2002). Blood lactate changes during isocapnic buffering in sprinters and long distance runners. Journal of physiological anthropology and applied human science, 21(3), 143-9.

Holmberg, H. C. (2015). The elite cross-country skier provides unique insights into human exercise physiology. Scandinavian Journal of Medicine \& Science in Sports, 25(4), 100-109. 
Hydren, J. R., Volek, J. S., Maresh, C. M., Comstock, B. A., \& Kraemer, W. J. (2013). Review of strength and conditioning for alpine ski racing. Strength \& Conditioning Journal, 35, 10-28.

Ivy, J. L., Withers, R. T., Van Handel, P. J., Elger, D. H., \& Costill, D. L. (1980). Muscle respiratory capacity and fiber type as determinants of the lactate threshold. Journal of applied physiology: respiratory, environmental and exercise physiology, 48, 523-527.

Lenti, M., De Vito, G., Scotto di Palumbo, A., Sbriccoli, P., Quattrini, F. M., et al. (2011). Effects of aging and training status on ventilatory response during incremental cycling exercise. Journal of strength and conditioning research, 25(5), 1326-1332.

Meyer, T., Faude, O., Scharhag, J., Urhausen, A., \& Kindermann, W. (2004). Is lactic acidosis a cause of exercise induced hyperventilation at the respiratory compensation point? British journal of sports medicine, 38, 622-625.

Mohr, M., Krustrup, P., Nielsen, J. J., Nybo, L., Rasmussen, M. K., et al. (2007). Effect of two different intense training regimens on skeletal muscle ion transport proteins and fatigue development. American journal of physiology, Regulatory, integrative and comparative physiology, 292, 1594-1602.

Nakagawa, Y.,\& Hattori, M. (2002).Relationship between muscle buffering capacity and fiber type during anaerobic exercise in human.Journal of physiological anthropology and applied human science, 21, 129131.

Oshima, Y., Miyamoto, T., Tanaka, S., Wadazumi, T., Kurihara, N., et al. (1997). Relationship between isocapnic buffering and maximal aerobic capacity in athletes. European journal of applied physiology and occupational physiology, 76, 409-14.

Oshima, Y., Tanaka, S., \& Miyamoto, T. (1998). Effects of endurance training above the anaerobic threshold on isocapnic buffering phase during incremental exercise in middle-distance runners. Japanese Journal of Physical Fitness and Sports Medicine, 47, 43-52.

Parkhouse, W. S., \& Mckenzie, D. C. (1984). Possible contribution of skeletal muscle buffer to enhanced anaerobic performance: a brief review. Medicine and science in sports and exercise, 16, 328-338.

Parkhouse, W. S., Mckenzie, D. C., Hochachka, P. W., \& Ovalle, W. K. (1985). Buffering capacity of deproteinized human vastuslateralis muscle. Journal of applied physiology, 58, 14-17.

Rausch, S. M., Whipp, B. J., Wasserman, K., \& Huszczuk, A. (1991). Role of the carotid bodies in the respiratory compensation for the metabolic acidosis of exercise in humans. The Journal of physiology, $444,567-78$.

Röcker, K., Striegel, H., Freund, T., \& Dickhuth, H. H. (1994). Relative functional buffering capacity in 400meter runners, long-distance runners and untrained individuals. European journal of applied physiology and occupational physiology, 68, 430-434.

Sandbakk, Ø., \& Holmberg, H. C. (2014). A reappraisal of success factors for olympic cross-country skiing. International journal of sports physiology and performance, 9(1), 117-21.

Seiler, K. S., \& Kjerland, G. Ø. (2006). Quantifying training intensity distribution in elite endurance athletes: is there evidence for an "optimal" distribution? Scandinavian Journal of Medicine \& Science in Sports, $16(1), 49-56$

Sharp, R. L., Costill, D. L., Fink, W. J., \& King, D. S. (1986). Effects of eight weeks of bicycle ergometer sprint training on human muscle buffer capacity. International Journal of Sports Medicine, 7, 13-17.

Staib, J. L., Im, J., Caldwell, Z., \& Rundell, K. W. (2000). Cross-country ski racing performance predicted by aerobic and anaerobic double poling power. Journal of strength and conditioning research, 14(3), 282288. 
Stringer, W., Wasserman, K., \& Casaburi, R. (1995). The VCO2/VO2 relationship during heavy, constant work rate exercise reflects the rate of lactic acid accumulation. European journal of applied physiology and occupational physiology, 72, 25-31.

Takano, N. (2000). Respiratory compensation point during incremental exercise as related to hypoxic ventilatory chemosensitivity and lactate increase in man. The Japanese journal of physiology, 50(4), 44955 .

Thalheimer, W., \& Cook, S. (2002). How to calculate effect sizes from published research articles: A simplified methodology. Available at: http://work learning.com/effect_sizes.htm. Accessed on January 11 (2016)

Wasserman, K., (1984). The anaerobic threshold measurement to evaluate exercise performance. American review of respiratory disease, 129, 35-40.

Whipp. B. J., Davis, J. A., \& Wasserman, K. (1989). Ventilatory control of the 'isocapnic buffering' region in rapidly-incremental exercise. Respiration physiology, 76(3), 357-67.

White, A.T., \& Johnson, S. C. (1991). Physiological comparison of international, national and regional alpine skiers. International Journal of Sports Medicine, 12(4), 374-378. 